\title{
Urologists' and GPs' knowledge of hereditary prostate cancer is suboptimal for prostate cancer counseling: a nation-wide survey in The Netherlands
}

\author{
Ruben Cremers $\cdot$ Christi van Asperen • \\ Paul Kil · Hans Vasen · Tjerk Wiersma • \\ Inge van Oort $\cdot$ Lambertus Kiemeney
}

Published online: 11 December 2011

(C) The Author(s) 2011. This article is published with open access at Springerlink.com

\begin{abstract}
A family history of prostate cancer (PCa) is an established risk factor for $\mathrm{PCa}$. In case of a positive family history, the balance between positive and adverse effects of prostate-specific antigen (PSA) testing might be different from the general population, for which the European Randomized Study of Screening for Prostate Cancer (ERSPC) showed a beneficial effect on mortality. This, however, went at the cost of considerable overtreatment. This study assessed Dutch physicians' knowledge of heredity and PCa and their 'post-ERSPC' attitude towards PCa testing, including consideration of family history. In January 2010, all Dutch urologists and clinical geneticists (CGs) and 300 general practitioners (GPs) were invited by email to complete an anonymous online survey, which contained questions about hereditary $\mathrm{PCa}$ and their attitudes towards $\mathrm{PCa}$ case-finding and screening.
\end{abstract}

R. Cremers · L. Kiemeney $(\varangle)$

Department of Epidemiology, Biostatistics and HTA (133),

Radboud University Nijmegen Medical Centre,

P.O. Box 9101, 6500 HB Nijmegen, The Netherlands

e-mail: b.kiemeney@ebh.umcn.nl

R. Cremers $\cdot$ H. Vasen

Netherlands Foundation for the Detection of Hereditary Tumors,

Leiden, The Netherlands

C. van Asperen

Department of Clinical Genetics, Leiden University Medical

Center, Leiden, The Netherlands

P. Kil

Department of Urology, St. Elisabeth Hospital, Tilburg,

The Netherlands

H. Vasen

Department of Gastroenterology and Hepatology, Leiden

University Medical Center, Leiden, The Netherlands
109 urologists (31\%), 69 GPs (23\%) and 46 CGs (31\%) completed the survey. CGs had the most accurate knowledge of hereditary PCa. All but 1 CG mentioned at least one inherited trait with $\mathrm{PCa}$, compared to only $25 \%$ of urologists and 9\% of GPs. CGs hardly ever counseled men about PCa testing. Most urologists and GPs discuss possible risks and benefits before testing for PCa with PSA. Remarkably, 35-40\% of them do not take family history into consideration. Knowledge of urologists and GPs about heredity and PCa is suboptimal. Hence, PCa counseling might not be optimal for men with a positive family history. Multidisciplinary guidelines on this topic should be developed to optimize personalized counseling.

Keywords Prostate cancer - Heredity - General practitioner · Urologist · Prostate-specific antigen .

Screening

T. Wiersma

Dutch College of General Practitioners, Utrecht,

The Netherlands

I. van Oort · L. Kiemeney

Department of Urology, Radboud University Nijmegen Medical

Centre, P.O. Box 9101, 6500 HB Nijmegen, The Netherlands

L. Kiemeney

Comprehensive Cancer Centre The Netherlands, Nijmegen,

The Netherlands 


\section{Introduction}

A positive family history of prostate cancer $(\mathrm{PCa})$ is an established risk factor for PCa. First-degree relatives of affected men have a 2-3 fold increased risk of PCa [1]. When 3 or more first-degree relatives are affected (or at least 2 first-degree relatives before the age of 55 years), the family is considered a 'Hereditary Prostate Cancer' (HPC) family according to the so-called Johns Hopkins or Carter criteria [2]. An estimated 5-10\% of PCa has a genetic cause. Yet, only a few very rare high-penetrance gene mutations have been identified to cause HPC [3]. In recent years, genome-wide association studies have added approximately 40 low-penetrance genetic polymorphisms that are associated with an increased risk of PCa $[4,5]$. Several polymorphisms have also been identified that are associated with serum prostate-specific antigen (PSA), the most commonly used marker for early detection of PCa [6, 7]. An ongoing matter of debate is whether PSA testing should be used for population-wide screening [8]. In a population-based setting, the European Randomized Study of Screening for Prostate Cancer (ERSPC) showed a decrease in PCa mortality of $31 \%$ in the screening arm after correction for non-attendance and contamination. However, this mortality reduction coincided with considerable overtreatment $[9,10]$. By contrast, the Prostate, Lung, Colorectal and Ovarian Cancer Screening Trial (PLCO), found no effect of PSA screening on mortality [11], but suffered from methodological problems which severely hamper interpretation of the results [12].

Previous studies into the effectiveness of PSA sceening in men with an increased risk due to family history have yielded largely inconsistent results. These range from a marked benefit for men in high-risk PCa families (particularly for families with early onset PCas) to a decreased risk of PCa for non-affected men in HPC families [13, 14]. The increasing use of PSA testing in the general population has also had an important influence on men with a family history of PCa. Men with a positive family history are relatively more active in pursuing PSA testing than men in the general population. This has led to an increased detection of mainly of small localized tumors [15].

To guide the public and physicians in translating the results of the ERSPC and PLCO into clinical practice, the Dutch Association of Urology (NVU) and the Dutch College of General Practitioners (NHG) concurrently released a policy statement in March 2009. This statement referred men to a website (http://www.prostaatwijzer.nl/) with information about PCa and PSA testing and advised them to consult their GP for further counseling [16]. It did, however, not discuss dealing with a family history of $\mathrm{PCa}$ or HPC. To date, in absence of official internationally accepted guidelines, the advice is to attempt to distinguish genetic predisposition-based families with multiple $\mathrm{PCa}$ cases from ascertainment-based multiple-case families and offer PCa screening only to the former [13].

This study assessed the knowledge of Dutch urologists, general practitioners (GPs) and clinical geneticists (CGs) about HPC and PCa as a phenotype in hereditary syndromes. Furthermore, their 'post-ERSPC' attitude towards $\mathrm{PCa}$ testing and the role of family history in clinical decision-making about PCa testing were assessed. To our knowledge, this is the first study to investigate this in different professions that counsel men about PCa testing.

\section{Materials and Methods}

After publication of the results of the ERSPC and PLCO and the statements of the NVU and NHG, an online survey was developed [17]. This survey, targeted at Dutch urologists, GPs and CGs, contained questions about HPC and assessed the participants' general attitude towards $\mathrm{PCa}$ testing. In addition to this, it inquired into the role that family history played in the physician's daily clinical practice regarding PCa testing. The survey also included case descriptions of a man requesting to be tested for PCa. This fictitious man presented at different ages, in absence of family history and physical complaints. The survey could be completed anonymously.

In January 2010, all Dutch urologists $(n=351)$, clinical oncogeneticists $(n=32)$, CGs in training $(n=50)$ and genetic counselors $(n=68)$ were invited by e-mail from their respective professional associations. GPs in the region of the Comprehensive Cancer Centre East (CCCE) who were enlisted to receive the CCCE's e-newsletter $(n=300)$ were invited by e-mail.

For statistical analysis, descriptive analyses were performed, stratified by profession. Because of small numbers, clinical oncogeneticists, CGs in training and genetic counselors were pooled into one stratum (CGs). Chi-square testing was used to test for differences between professions. Participants who never counseled men about PCa testing were excluded from the analysis.

\section{Results}

In total, 225 surveys were completed (overall response rate $28 \%$ ). These were submitted by 109 urologists $(31 \%), 69$ GPs (23\%) and 46 CGs (31\%). One pediatric urologist and two CGs were excluded from analyses because they never counseled men for PCa testing. Occasionally, participants did not complete all questions, causing small differences in the subtotals for different questions. Of the urologists, $66 \%$ (71/107) counseled men about PCa testing at least once a week and 93\% (100/107) did this at least once a month. 
In comparison, $85 \%$ of the GPs (59/69) did this at least once a month, as opposed to only $2 \%(1 / 44)$ of the CGs.

By contrast, the CGs had the most accurate knowledge of the HPC criteria: $72 \%$ (31/43) correctly selected the minimum of three affected first-degree relatives for the criterion that is most frequently fulfilled (Table 1). In comparison, only $36 \%(38 / 105)$ of the urologists and $18 \%$ $(12 / 66)$ of the GPs correctly selected this criterion $(P<0.001)$. A majority of the GPs $(59 \%)$ indicated not to know this definition. CGs were also best informed about the number of affected first-degree relatives with a PCa diagnosis before 55 years of age to meet the definition of HPC, although the differences between the groups were smaller. The third definition of HPC, i.e., three consecutive generations with PCa, was known to only a few participants.

Almost all CGs $(41 / 42,98 \%)$ listed at least one inherited trait with $\mathrm{PCa}$ as part of the phenotype, compared to only $24 \%(25 / 103)$ of the urologists and $9 \%(6 / 66)$ of the GPs.

Table 1 Responses to the question "What is the minimum number of relatives with prostate cancer to meet the Carter criteria for hereditary prostate cancer (HPC)?"

\begin{tabular}{|c|c|c|c|}
\hline & Urologists & GPs & CGs \\
\hline \multicolumn{4}{|c|}{ Number of affected first-degree relatives (all ages) ${ }^{\dagger}$} \\
\hline Two & $35(33 \%)$ & $9(14 \%)$ & $1(2 \%)$ \\
\hline Three & $38(36 \%)$ & $12(18 \%)$ & $31(72 \%)$ \\
\hline Four & $1(1 \%)$ & $2(3 \%)$ & $2(5 \%)$ \\
\hline$>$ Four & $3(3 \%)$ & $0(0 \%)$ & $1(2 \%)$ \\
\hline Don't know & $15(14 \%)$ & $39(59 \%)$ & $7(16 \%)$ \\
\hline Not a criterion & $13(12 \%)$ & $4(6 \%)$ & $1(2 \%)$ \\
\hline Total & 105 & 66 & 43 \\
\hline \multicolumn{4}{|c|}{$\begin{array}{l}\text { Number of affected first-degree relatives (diagnosis }<55 \text { years of } \\
\text { age) })^{\dagger}\end{array}$} \\
\hline Two & $72(68 \%)$ & $33(48 \%)$ & $34(76 \%)$ \\
\hline Three & $6(6 \%)$ & $0(0 \%)$ & $3(7 \%)$ \\
\hline Four & $1(1 \%)$ & $1(1 \%)$ & $0(0 \%)$ \\
\hline$>$ Four & $5(5 \%)$ & $2(3 \%)$ & $0(0 \%)$ \\
\hline Don't know & $12(11 \%)$ & $32(46 \%)$ & $7(16 \%)$ \\
\hline Not a criterion & $10(9 \%)$ & $1(1 \%)$ & $1(2 \%)$ \\
\hline Total & 106 & 69 & 45 \\
\hline \multicolumn{4}{|c|}{ Number of consecutive generaties with prostate cancer ${ }^{\dagger}$} \\
\hline Two & $10(10 \%)$ & $10(15 \%)$ & $9(21 \%)$ \\
\hline Three & $15(15 \%)$ & $6(9 \%)$ & $5(11 \%)$ \\
\hline Four & $3(3 \%)$ & $1(2 \%)$ & $1(2 \%)$ \\
\hline$>$ Four & $2(2 \%)$ & $1(2 \%)$ & $0(0 \%)$ \\
\hline Don't know & $25(25 \%)$ & $39(58 \%)$ & $10(23 \%)$ \\
\hline Not a criterion & $44(44 \%)$ & $10(15 \%)$ & $19(43 \%)$ \\
\hline Total & 99 & 67 & 44 \\
\hline
\end{tabular}

${ }^{\dagger} P \leq 0.001$ for differences between the physician groups Correct answers are italicized
The most frequently mentioned traits were the $B R C A 2$ gene mutation $(n=60)$, the $B R C A l$ gene mutation $(n=40)$ and Lynch syndrome $(n=10)$. The rare $H P C 1, H P C X, M S R 1$, RNASEL and HPC2/ELAC2 mutations were sporadically mentioned.

Urologists had the least reservations towards PCa testing in a man with no physical complaints and no family history of PCa: $46 \%(32 / 69)$ of the GPs and $49 \%$ (22/45) of the CGs preferred to refrain from testing unless there were strong reasons to test (Table 2), as compared to $31 \%$ (33/ 108) of the urologists. For a man presenting at 55 and 75 years of age, urologists and GPs gave similar answers. Between 70 and $80 \%$ of them would first inform him about the possible benefits and risks of PCa testing. CGs were more inclined not to test for PCa. At 45 years of age, more physicians in all groups would not test for PCa.

Age played a role when considering PCa testing. Of the urologists, $70 \%$ reported to use age limits, with 45 years as the mean and median lower age limit. This lower age limit was higher for GPs (60\% reported age limits) and CGs (30\% reported age limits), with 50 years of age being the median lower age limit. The median maximum age limit was 80 years (mean 77) for urologists and GPs, compared to 75 years (mean 74) for CGs. CGs always took family history into consideration when deciding whether or not to test for PCa. By contrast, 35-40\% of urologists and GPs answered that family history would not influence the decision whether or not to test for PCa (Table 3). This did not vary between physicians with different general attitudes towards PSA testing $(P=0.47$ for the urologists and $P=0.78$ for the GPs), as was assessed in a previous question.

A majority of the urologists (76\%) knew the ERSPC and PLCO results, compared to only 14 and $8 \%$ of CGs and GPs, respectively. Ninety-two percent (75/82) of the urologists who knew the studies found the ERSPC results more valuable. The statements of NVU and NHG, advising men to visit the website and consult the GP if further counseling was needed, were better known than the results of the trials: $85 \%(92 / 108)$ of the urologists and $59 \%$ (41/69) of the GPs was familiar with the statements. Of them, $12 \%(11 /$ 91) of the urologists and $24 \%$ (10/41) of the GPs did not agree with the statements. Only 2 of the 43 CGs (5\%) were familiar with the statements.

\section{Discussion}

A positive family history of $\mathrm{PCa}$ is an important risk factor for PCa and the balance between pros and cons of PSA testing may be different in men with affected relatives. It is therefore remarkable that urologists and GPs are poorly informed about HPC. Only one in three urologists and one 
Table 2 Responses to the question "Would you test this man for PCa?" regarding a man with no physical complaints/no family history of PCa, requesting to be tested for $\mathrm{PCa}$

\begin{tabular}{|c|c|c|c|c|}
\hline Age at presentation & Test for prostate cancer & Urologists & GPs & CGs \\
\hline \multirow[t]{4}{*}{ General attitude $^{\mathrm{a}}$} & Will test, unless... & $35(32 \%)$ & $13(19 \%)$ & $3(7 \%)$ \\
\hline & Will not test, unless... & $33(31 \%)$ & $32(46 \%)$ & $22(49 \%)$ \\
\hline & Leave choice to patient & $37(34 \%)$ & $22(32 \%)$ & $9(20 \%)$ \\
\hline & Other* & $3(3 \%)$ & $2(3 \%)$ & $11(25 \%)$ \\
\hline \multirow[t]{3}{*}{45 years of age } & Yes & $20(19 \%)$ & $5(7 \%)$ & $1(2 \%)$ \\
\hline & No & $12(11 \%)$ & $18(26 \%)$ & $28(64 \%)$ \\
\hline & First discuss pros and cons of prostate cancer testing & $75(70 \%)$ & $46(67 \%)$ & $15(34 \%)$ \\
\hline \multirow[t]{3}{*}{55 years of age ${ }^{b}$} & Yes & $29(27 \%)$ & $16(23 \%)$ & $1(2 \%)$ \\
\hline & No & $0(0 \%)$ & $1(1 \%)$ & $16(36 \%)$ \\
\hline & First discuss pros and cons of prostate cancer testing & $79(73 \%)$ & $52(75 \%)$ & $27(61 \%)$ \\
\hline \multirow[t]{3}{*}{75 years of age ${ }^{c}$} & Yes & $21(19 \%)$ & $10(15 \%)$ & $9(21 \%)$ \\
\hline & No & $8(7 \%)$ & $3(4 \%)$ & $14(33 \%)$ \\
\hline & First discuss pros and cons of prostate cancer testing & $79(73 \%)$ & $56(81 \%)$ & $20(47 \%)$ \\
\hline
\end{tabular}

* Answers under "Other": most often (8/11) CGs indicated not to perform this kind of testing themselves, but would refer the man to their GP

${ }^{a} P<0.001$ for differences between the physician groups

${ }^{\mathrm{b}}$ No significant difference between urologists and GPs; $P=0.40$

${ }^{c}$ No significant difference between urologists and GPs; $P=0.45$

Table 3 Responses to the question (A) "Does family history play a role in the decision whether or not to test a man for PCa?" and the follow-up question (B) "How extensively do you inquire about the family history?"

\begin{tabular}{|c|c|c|c|}
\hline & Urologists & GPs & CGs \\
\hline \multicolumn{4}{|c|}{ A. Does family history play a role? } \\
\hline Yes & $67(62 \%)$ & $44(65 \%)$ & $40(98 \%)$ \\
\hline No & $41(38 \%)$ & $24(35 \%)$ & $1(2 \%)$ \\
\hline Total & 108 & 68 & 41 \\
\hline \multicolumn{4}{|c|}{ B. Extent of inquiring about the family history? } \\
\hline Only PCa & $29(43 \%)$ & $16(37 \%)$ & $0(0 \%)$ \\
\hline PCa and other malignancies & $38(57 \%)$ & $27(63 \%)$ & $40(100 \%)$ \\
\hline Total & 67 & 43 & 40 \\
\hline
\end{tabular}

in five GPs is familiar with the criteria for HPC. Almost $60 \%$ of the GPs indicated not to know the definition. CGs were better informed, but they hardly ever counsel men about PCa testing.

The BRCAl gene mutation was frequently selected as an inherited trait with $\mathrm{PCa}$ as part of the phenotype. The evidence for an increased risk of PCa due to a $B R C A 1$ gene mutation is quite weak, though. By contrast, for $B R C A 2$ gene mutations (selected by 14 urologists and all 42 CGs) there is fairly solid evidence of familial clustering of aggressive $\mathrm{PCa}$ $[18,19]$. Lynch syndrome was also selected 10 times, 7 times of which by urologists. Recently, an elevated risk of PCa for carriers of a mismatch-repair gene mutation was indeed found [20]. This has, however, not been confirmed in other studies, so it remains unclear whether the physicians who selected Lynch syndrome are correct. It should be noted that urologists and GPs hardly ever counsel patients with an elevated PCa risk based on these inherited traits.

In general, urologists reported the least reservations towards PCa testing and would test at a younger age than GPs and CGs. However, the majority of urologists and GPs stated to first discuss the risks and benefits of PSA testing and only test if a man would still want to be tested. So, even though $41 \%$ of GPs was not familiar with the statements regarding PCa testing and $92 \%$ of them did not know the ERSPC and PLCO results, they adhered just as well to the guidelines as the urologists. Participants who disagreed with the NVU/NHG statements, mostly indicated that the statements lacked attention for patients' preferences.

In contrast with the urologists and GPs, CGs would more often not test for PCa. This might be explained by the fact that the CGs mainly have an advisory role and refer their patients to a GP or urologist for PCa testing. CGs hardly ever counsel men about PCa testing, as there is no frequently occurring genetic defect known to cause PCa. This may change, however, when more data become available about the risk of $\mathrm{PCa}$ among $B R C A 2$ carriers. An international study is currently examining this risk (www.impact-study.co.uk).

One of the most striking observations might be that more than one in three urologists and GPs would not take family history into account when deciding whether or not to test a man for PCa. Intuitively, one would think that men with a positive family history, and thus a higher a priori 
risk of $\mathrm{PCa}$, would benefit more from PSA screening. Arguing against this is that HPC cases do not seem to differ from sporadic cases with respect to Gleason scores and PCa-specific survival [21, 22]. Even more so, screening programs amongst non-affected men in HPC families have shown that the chance of finding $\mathrm{PCa}$ in non-affected men in HPC families is low [13].

Although we did not address this in our study, when a man requesting $\mathrm{PCa}$ testing does have, e.g., an affected brother, he will very likely be tested, not in the least for reasons of anxiety management. However, whether this is beneficial, is doubtful. To better guide physicians in this matter, an addendum to PCa guidelines should be developed in a multidisciplinary collaborative effort, describing how to deal with PCa testing in case of a positive family history and HPC. The conclusion from a previous study to assess the extent and nature of the family history (predisposition-based vs. ascertainment-based) might well serve as a starting point for such a guideline [13]. In addition to this, the use of decision aids, e.g., the SWOP-PRI should be promoted [23], as they already include the effect of family history in the risk estimates.

The results of this study should be interpreted with some caution. Although the responder groups were reasonably large in absolute numbers, the response rate was only $31 \%$ at best (for urologists and CGs). Hence, it is difficult to extrapolate the results to all Dutch physicians providing $\mathrm{PCa}$ counseling. Even more so, if physicians with more interest in this topic completed the survey more often, the results regarding knowledge about HPC and adherence to guidelines might be overoptimistic. On the other hand, intuitively physicians who take care of most of the counseling are most eager to complete the survey. It is also important to bear in mind that the results may not easily be extrapolated to other countries as they may be influenced by the health care system. In The Netherlands, e.g., men cannot visit a urologist without a referral from their GP.

In conclusion, the majority of urologists and GPs adhered to PCa testing guidelines. However, these guidelines do not include family history and many physicians indicated not to consider family history. Hence, PCa counseling might not be optimal for men with a positive family history. We propose that additional guidelines on this topic are developed in a multidisciplinary effort to optimize counseling.

Acknowledgments We thank the Dutch Association of Urology, the Comprehensive Cancer Centre The Netherlands (location Nijmegen) and the professional organizations of the Dutch clinical geneticists, clinical geneticists in training and genetic counselors for the distribution of the survey. Dr. Cremers was supported by Contract Number 202059 (ProMark) from the Seventh Framework Program from the European Union.
Conflict of interest The authors declare that they have no conflict of interest.

Open Access This article is distributed under the terms of the Creative Commons Attribution Noncommercial License which permits any noncommercial use, distribution, and reproduction in any medium, provided the original author(s) and source are credited.

\section{References}

1. Brandt A, Bermejo JL, Sundquist J, Hemminki K (2010) Agespecific risk of incident prostate cancer and risk of death from prostate cancer defined by the number of affected family members. Eur Urol 58(2):275-280

2. Carter BS, Bova GS, Beaty TH, Steinberg GD, Childs B, Isaacs WB, Walsh PC (1993) Hereditary prostate cancer: epidemiologic and clinical features. J Urol 150(3):797-802

3. Langeberg WJ, Isaacs WB, Stanford JL (2007) Genetic etiology of hereditary prostate cancer. Front Biosci 12:4101-4110

4. Fletcher O, Houlston RS (2010) Architecture of inherited susceptibility to common cancer. Nat Rev Cancer 10(5):353-361

5. Varghese JS, Easton DF (2010) Genome-wide association studies in common cancers-what have we learnt? Curr Opin Genet Dev 20(3):201-209

6. Gudmundsson J, Besenbacher S, Sulem P, Gudbjartsson DF, Olafsson I, Arinbjarnarson S, Agnarsson BA, Benediktsdottir KR, Isaksson HJ, Kostic JP, Gudjonsson SA, Stacey SN, Gylfason A, Sigurdsson A, Holm H, Bjornsdottir US, Eyjolfsson GI, Navarrete S, Fuertes F, Garcia-Prats MD, Polo E, Checherita IA, Jinga M, Badea P, Aben KK, Schalken JA, van OI, Sweep FC, Helfand BT, Davis M, Donovan JL, Hamdy FC, Kristjansson K, Gulcher JR, Masson G, Kong A, Catalona WJ, Mayordomo JI, Geirsson G, Einarsson GV, Barkardottir RB, Jonsson E, Jinga V, Mates D, Kiemeney LA, Neal DE, Thorsteinsdottir U, Rafnar T, Stefansson K (2010) Genetic correction of PSA values using sequence variants associated with PSA levels. Sci Transl Med 2(62):62ra92

7. Kote-Jarai Z, Amin Al Olama A, Leongamornlert D, Tymrakiewicz M, Saunders E, Guy M, Giles GG, Severi G, Southey M, Hopper JL, Sit KC, Harris JM, Batra J, Spurdle AB, Clements JA, Hamdy F, Neal D, Donovan J, Muir K, Pharoah PD, Chanock SJ, Brown N, Benlloch S, Castro E, Mahmud N, O'Brien L, Hall A, Sawyer E, Wilkinson R, Easton DF, Eeles RA (2011) Identification of a novel prostate cancer susceptibility variant in the KLK3 gene transcript. Hum Genet 129(6):687-694. doi:10.1007/ s00439-011-0981-1

8. Stamey TA, Yang N, Hay AR, McNeal JE, Freiha FS, Redwine E (1987) Prostate-specific antigen as a serum marker for adenocarcinoma of the prostate. N Engl J Med 317(15):909-916

9. Roobol MJ, Kerkhof M, Schroder FH, Cuzick J, Sasieni P, Hakama M, Stenman UH, Ciatto S, Nelen V, Kwiatkowski M, Lujan M, Lilja H, Zappa M, Denis L, Recker F, Berenguer A, Ruutu M, Kujala P, Bangma CH, Aus G, Tammela TL, Villers A, Rebillard X, Moss SM, de Koning HJ, Hugosson J, Auvinen A (2009) Prostate cancer mortality reduction by prostate-specific antigen-based screening adjusted for nonattendance and contamination in the European Randomised Study of Screening for Prostate Cancer (ERSPC). Eur Urol 56(4):584-591

10. Schroder FH, Hugosson J, Roobol MJ, Tammela TL, Ciatto S, Nelen V, Kwiatkowski M, Lujan M, Lilja H, Zappa M, Denis LJ, Recker F, Berenguer A, Maattanen L, Bangma $\mathrm{CH}$, Aus G, Villers A, Rebillard X, van der KT, Blijenberg BG, Moss SM, de Koning HJ, Auvinen A (2009) Screening and prostate-cancer 
mortality in a randomized European study. $\mathrm{N}$ Engl $\mathrm{J}$ Med 360(13):1320-1328

11. Andriole GL, Crawford ED, Grubb RL III, Buys SS, Chia D, Church TR, Fouad MN, Gelmann EP, Kvale PA, Reding DJ, Weissfeld JL, Yokochi LA, O’Brien B, Clapp JD, Rathmell JM, Riley TL, Hayes RB, Kramer BS, Izmirlian G, Miller AB, Pinsky PF, Prorok PC, Gohagan JK, Berg CD (2009) Mortality results from a randomized prostate-cancer screening trial. N Engl J Med 360(13):1310-1319

12. Schroder FH, Roobol MJ (2010) ERSPC and PLCO prostate cancer screening studies: what are the differences? Eur Urol 58(1):46-52

13. Kiemeney LA, Broeders MJ, Pelger M, Kil PJ, Schroder FH, Witjes JA, Vasen HF (2008) Screening for prostate cancer in Dutch hereditary prostate cancer families. Int J Cancer 122(4): 871-876

14. Valeri A, Cormier L, Moineau MP, Cancel-Tassin G, Azzouzi R, Doucet L, Baschet F, Cussenot I, L'Her J, Berthon P, Mangin P, Cussenot O, Morin JF, Fournier G (2002) Targeted screening for prostate cancer in high risk families: early onset is a significant risk factor for disease in first degree relatives. J Urol 168(2):483-487. doi:S0022-5347(05)64663-0

15. Bratt O, Garmo H, Adolfsson J, Bill-Axelson A, Holmberg L, Lambe M, Stattin P (2010) Effects of prostate-specific antigen testing on familial prostate cancer risk estimates. J Natl Cancer Inst 102(17):1336-1343. doi:10.1093/jnci/djq265

16. Dutch Association of Urology (2009) Public statement on the point of view regarding the results of the European randomised study of screening for prostate cancer (in Dutch). Available at: http://www. nvu.nl/leden/nieuws/proxy?urlProxy=/root/news4/standpuntbepaling -nederlandse-vereniging-voor-urologie-aangaande-resultaten-van-eu ropees-screeningsonderzoek-voor-prostaatkanker\&objectSynopsis=
27dvQhiqyaNz7FDkExL3dA\#SAHIZdeHA0JqE2GGNUP6ng. Date accessed 11 Oct 2011

17. Cremers RG, van Asperen CJ, Kil PJ, Vasen HF, Wiersma T, van Oort IM, Kiemeney LA (2011) Online survey (in Dutch). Available at: http://www.prostaatkanker-erfelijkheidenscreening. nl/vragenlijst/prca.htm. Date accessed 11 Oct 2011

18. Liede A, Karlan BY, Narod SA (2004) Cancer risks for male carriers of germline mutations in BRCA1 or BRCA2: a review of the literature. J Clin Oncol 22(4):735-742

19. Narod SA, Neuhausen S, Vichodez G, Armel S, Lynch HT, Ghadirian P, Cummings S, Olopade O, Stoppa-Lyonnet D, Couch F, Wagner T, Warner E, Foulkes WD, Saal H, Weitzel J, Tulman A, Poll A, Nam R, Sun P, Danquah J, Domchek S, Tung N, Ainsworth P, Horsman D, Kim-Sing C, Maugard C, Eisen A, Daly M, McKinnon W, Wood M, Isaacs C, Gilchrist D, Karlan B, Nedelcu R, Meschino W, Garber J, Pasini B, Manoukian S, Bellati C (2008) Rapid progression of prostate cancer in men with a BRCA2 mutation. Br J Cancer 99(2):371-374

20. Grindedal EM, Moller P, Eeles R, Stormorken AT, Bowitz-Lothe IM, Landro SM, Clark N, Kvale R, Shanley S, Maehle L (2009) Germ-line mutations in mismatch repair genes associated with prostate cancer. Cancer EpidemiolBiomarkers Prev 18(9): 2460-2467

21. Gronberg H, Damber L, Tavelin B, Damber JE (1998) No difference in survival between sporadic, familial and hereditary prostate cancer. Br J Urol 82(4):564-567

22. Kupelian PA, Reddy CA, Reuther AM, Mahadevan A, Ciezki JP, Klein EA (2006) Aggressiveness of familial prostate cancer. J Clin Oncol 24(21):3445-3450

23. Kranse R, Roobol M, Schroder FH (2008) A graphical device to represent the outcomes of a logistic regression analysis. Prostate 68(15):1674-1680 